\title{
Intervençóes da terapia ocupacional junto aos sujeitos afastados do trabalho por LER/DORT
}

\author{
Maria do Carmo Baracho de Alencar \\ Universidade Federal de São Paulo - UNIFESP, Santos, SP, Brasil.
}

\begin{abstract}
Resumo: O objetivo deste artigo é relatar a experiência de atendimentos de alunos em estágio profissionalizante do curso de Terapia Ocupacional da Universidade Federal de São Paulo - UNIFESP/BS, no Centro de Referência em Saúde do Trabalhador-CEREST, em Santos-SP, no ano de 2011, junto aos sujeitos em situação de afastamento do trabalho por LER/DORT. Metodologia: Os procedimentos envolveram o encaminhamento de médicos e de outros profissionais de sujeitos acometidos por LER/DORT para avaliações individuais, com roteiro pré-elaborado, análises e planejamentos para atendimentos individuais e em grupos. Resultados: Participaram deste estudo 28 sujeitos $(n=28)$ de ambos os gêneros, com prevalência do gênero feminino, faixa etária de 35 a 55 anos, de diferentes níveis de escolaridade e profissões. Foram realizados 178 atendimentos individuais e 84 atendimentos em grupos, sendo dois grupos temáticos e três oficinas terapêuticas. Por meio dos atendimentos individuais e em grupos, os sujeitos se mostraram mais confiantes e dispostos, melhorando o autocuidado e as percepções pessoais em relação às habilidades e possibilidades, sendo as intervenções em grupos fundamentais para trocas de experiências e vivências. Conclusões: Os resultados evidenciaram a importância da atuação da Terapia Ocupacional junto aos sujeitos em situação de afastamento do trabalho por LER/DORT, e com dores crônicas.
\end{abstract}

Palavras-chave: Licença Médica, Terapia Ocupacional, Transtornos Traumáticos Cumulativos, Saúde do Trabalhador.

\section{Occupational therapy interventions next to retired from work due to RSI subjects}

\begin{abstract}
This study aimed to report the experience of the Occupational Therapy undergraduation students in a professional internship at the Universidade Federal de São Paulo - UNIFESP/BS, in the Reference Center of Occupational Health of Santos-SP, during 2011 with subjects retired from work due to RSI/WMSD. Methodology: The procedures involved medical and other professional referrals of the subjects with RSI/WMSD for individual evaluations, with a pre-elaborated script, analyses and planning for individual and group appointments. Results: Twenty-eight subjects $(n=28)$ from both gender participated on the study, with female prevalence, aged between 35 and 55 years old, and with different school level and occupations. There were 178 individual, and 84 group appointments, two thematic groups and three Therapeutic Workshops. Through the individual and group appointments subjects were more confident and willing, improving self-care and personal perceptions related to abilities and possibilities, being the group interventions fundamental to exchange life experiences. Conclusion: The results evidence the importance of occupational therapy interventions for subjects retired from work due to RSI/WMSD, and with chronic pain.
\end{abstract}

Keywords: Sick Leave, Occupational Therapy, Repetitive Strain Injury, Occupational Health. 


\section{Introdução}

Muitas transformaçôes ocorreram no mundo do trabalho com avanços tecnológicos, globalização, capitalismo desenfreado, imposição de novas exigências junto aos trabalhadores, novas relaçóes de poder, novos contratos de prestação de serviços, entre outros, que vêm afetando a saúde dos trabalhadores em diversos aspectos. A necessidade de formação ou de qualificação/requalificação constante tem sido estimulada, e o desemprego e demais formas de precarização influenciam, de maneira perversa, o posicionamento dos indivíduos no mundo do trabalho (HENNINGTON, 2011). Segundo a autora, difunde-se a ideia de parceria e colaboração, como uma suposta comunhão de objetivos e interesses entre capital e trabalho, o que, na prática, tem levado à intensificação do trabalho e à subordinação do trabalhador coletivo ao capital.

As transformaçóes do mundo do trabalho têm repercussóes sobre a saúde dos trabalhadores, tanto no aspecto físico quanto mental. Dentre as formas de adoecimento no mundo contemporâneo, estão as Lesôes por esforços repetitivos (LER) ou os Distúrbios osteomusculares relacionados ao trabalho (DORT), que continuam crescendo entre a população de trabalhadores e, muitas vezes, levando-os ao afastamento do trabalho. As doenças do sistema osteomuscular estão entre as principais causas de benefícios concedidos junto ao Instituto Nacional do Seguro Social - INSS (WALSH et al., 2004; ALMEIDA; BARBOSA-BRANCO, 2011). As LERs/DORTs correspondem a um conjunto de afecçôes relacionadas às atividades laborativas que acomete músculos, fáscias musculares, tendôes, ligamentos, articulaçôes, nervos, vasos sanguíneos e tegumento (YENG et al., 2001). Esse grupo de transtornos tem o aparecimento e evolução de caráter insidioso, e origens multifatoriais complexas (BRASIL, 2001).

No Brasil, ao longo dos últimos dez anos, ocorreu grande prevalência das doenças osteomusculares e há indicaçôes de que a expansão da violência psicológica esteja associada à origem de quadros de depressão em frequente comorbidade com os casos de LER/DORT (ELKELES; SELIGMAN-SILVA, 2010). Entre os aspectos de risco para LER/DORT, estão: intensificação e sobrecarga daqueles que permanecem no mundo do trabalho, aumento de movimentos repetitivos, ritmo acelerado, posturas corporais inadequadas, além de aspectos relacionados à organização do trabalho, como dificuldades na divisão e relaçôes entre os trabalhadores, hierarquia rígida, relaçốes de poder autoritárias, pressão de chefia, desconfiança e competição entre os pares, obrigação na realização de horas extras, entre outros (LANCMAN; GHIRARDI, 2002).

A LER/DORT tem acometido homens e mulheres em plena fase produtiva, e tem causado inúmeros afastamentos do trabalho, cuja quase totalidade evolui para a incapacidade parcial e, em alguns casos, para a incapacidade permanente (BUCKLE, 2005). Segundo Crook e Moldofsky (1995), embora alguns estudos tragam bons prognósticos para alguns casos, as lesões musculoesqueléticas consomem recursos consideráveis em atendimento médico, absenteísmo no trabalho e benefícios previdenciários.

A experiência do afastamento do trabalho por adoecimento profissional está marcada social e historicamente pela incapacidade para o trabalho e pela insegurança (RAMOS; TITTONI; NARDI, 2008). Para os autores, há o risco do desemprego e dificuldades encontradas na chamada via crucis institucional legal, em que o trabalhador necessita comprovar o vínculo entre seu adoecimento e seu trabalho para integrar os benefícios a que tem direito em sua condição. O não reconhecimento pelo INSS de doenças comprovadamente relacionadas ao trabalho é frequente nas LERs/DORTs (SALERMO; SILVESTRE; SABINO, 2011). Existe uma dificuldade para se comprovar o nexo causal da doença, embora existam inúmeras condiçốes desfavoráveis no trabalho que podem estar relacionadas ao aparecimento das LERs/DORTs nos trabalhadores; observa-se que apenas $2 \%$ das empresas fazem o registro da Comunicação de Acidente do Trabalho (CAT), dificultando a garantia dos direitos do trabalhador (LEITE; SILVA; MERIGHI, 2007).

Uma vez afastados do trabalho, os sujeitos convivem com dores crônicas em atividades cotidianas e revelam sentimentos de inutilidade, de revolta, decorrentes da situação de afastamento do trabalho (GAEDKE; KRUG, 2008; ALENCAR; OTA, 2011). As repercussões biopsicossociais dos DORTs são inúmeras, pois causam dor crônica, incapacidade física, impactos legais, sociais, econômicos e psicológicos, que requerem, entre outros, enfoque amplo e multidimensional (LIN et al., 2001). Em sujeitos com dores crônicas, os objetivos terapêuticos vão girar em torno de retomar as atividades cotidianas, recuperar a função e sair do isolamento social, apesar da permanência da dor (LIMA; TRAD, 2007). A lesão física com dor crônica tem sido considerada um indicador para intervençóes da Terapia Ocupacional (SKJUTAR et al., 2010).

A Terapia Ocupacional na Saúde do Trabalhador atua tanto na prevençáo como na promoção e na reabilitação de trabalhadores. Os terapeutas ocupacionais 
começam a compor as equipes no Departamento de Saúde Ocupacional e nos Serviços de Segurança e Medicina do Trabalho das empresas, e vêm colaborando na prevenção de agravos, afastamentos e aposentadorias precoces, e na percepçáo de riscos de acidentes ou adoecimentos, entre outros (LANCMAN, 2004). Segundo Watanabe e Nicolau (2001), os terapeutas ocupacionais nos Centros de Referência em Saúde do Trabalhador estão articulados com as demais açôes de saúde em uma equipe multidisciplinar, realizando, em geral, três atividades: assistência aos trabalhadores; vigilância das condiçôes de trabalho e postos de trabalho nas empresas, e educação em saúde e trabalho. A Terapia Ocupacional vem contribuindo na abordagem relativa ao meio social e às relaçôes interindividuais e coletivas, visando à atenção integral do trabalhador (RODRIGUES; SIMONELLI; LIMA, 2013). A Terapia Ocupacional tem o objetivo de promover a autonomia, a criação de espaços para o viver e expressar-se, considerando as relaçóes sociais como parte fundamental do processo de reabilitaçáo e/ou reinserção no trabalho (GUTTERRES; BARKNECHT, 2005).

O Centro de Referência em Saúde do Trabalhador (CEREST) do município de Santos é uma unidade de saúde criada em 1990, com o objetivo de identificar, tratar e prevenir agravos e doenças relacionados ao trabalho. O CEREST é um serviço do Sistema Único de Saúde (SUS), vinculado a Coordenadoria de Vigilância em Saúde da Prefeitura Municipal de Santos, sendo habilitado, em 2003, pelo Ministério da Saúde, como referência regional aos municípios de Santos, São Vicente e Guarujá.

O objetivo deste artigo é relatar a experiência de atendimentos junto aos sujeitos em situaçáo de afastamento do trabalho por LER/DORT em estágio profissionalizante do curso de Terapia Ocupacional da Universidade Federal de Sáo Paulo - UNIFESP/BS, no Centro de Referência em Saúde do Trabalhador - CEREST, no município de Santos-SP, no período de janeiro a dezembro de 2011.

\section{Procedimentos e métodos}

O estágio profissionalizante contou com a participação de alunos do $4 .^{\circ}$ ano do curso de Terapia Ocupacional da Universidade Federal de São Paulo - UNIFESP, Campus da Baixada Santista, e com atividades junto ao Centro de Referência em Saúde do Trabalhador - CEREST/Santos. Foram programados atendimentos individuais e em grupos junto aos sujeitos em situação de afastamento do trabalho, com diagnósticos clínicos estabelecidos ou em processos de investigação para LER/DORT.
O estágio teve início no ano de 2009 e, para este relato de experiência, foi escolhido aleatoriamente o período de janeiro a dezembro de 2011.

O estágio neste local ocorreu duas vezes por semana, com duração de nove horas semanais. Entre alguns critérios para o encaminhamento para a Terapia Ocupacional, estipulou-se, além de diagnósticos clínicos estabelecidos e/ou em processos de investigação para LER/DORT, apresentar sintomas crônicos, com ou sem sintomas depressivos e/ou outros transtornos mentais diagnosticados clinicamente. Inicialmente, os encaminhamentos para a Terapia Ocupacional foram realizados por médicos e outros profissionais de saúde da própria unidade, para avaliação inicial.

\subsection{As avaliações individuais em Terapia Ocupacional}

Os sujeitos encaminhados foram avaliados individualmente pelos alunos, sob supervisão de estágio, e as avaliaçốes inicialmente consistiam de entrevistas semiestruturadas, com roteiro pré-elaborado, contendo dados gerais, como identificação, idade, estado civil, escolaridade, com quem reside atualmente, se tem filhos, quantos filhos, última profissão, médico responsável e dominância de mão. $\mathrm{O}$ número do prontuário também era registrado e sempre consultado a fim de manter o contato com as informaçôes clínicas.

Algumas questôes foram investigadas neste momento: tempo de afastamento, do que foi afastado, como ocorreu o adoecimento, como se sentiu, situação atual junto ao Instituto Nacional do Seguro Social - INSS, junto aos diagnósticos clínicos, queixas atuais principais, sintomas, regiōes corporais acometidas, sintomas que estavam interferindo no cotidiano de vida, quando ocorriam, o que piorava, o que melhorava, entre outras questóes. Ainda, se fez cirurgia, há quanto tempo, como se sentia em relação à cirurgia (recuperação), entre outras. Alguns registros eram realizados no momento, em papel e caneta, com um roteiro em mãos.

$\mathrm{O}$ aluno, neste momento, propiciava um momento de acolhimento com escuta e buscava atentamente alguns aspectos que pudessem ser relevantes, não se fixando, em alguns casos, ao roteiro pré-estabelecido, mas sim às questôes pertinentes ao momento e junto ao sujeito, aspectos pertinentes também ao processo de aprendizagem. Buscou-se uma escuta clínica, em que o terapeuta ocupacional visava encontrar elementos importantes, nos conteúdos manifesto e latente. Muitas vezes, eram necessários de dois a 
três encontros para essa investigação inicial e para o planejamento de intervenções clínicas em Terapia Ocupacional, sempre discutidas em supervisão. Foram utilizados também como complemento outros instrumentos de avaliaçáo, entre eles o Health Assesment Questionnaire - HAQ (FERRAZ et al., 1990), que investiga sobre algumas dificuldades funcionais em atividades básicas e instrumentais de vida diária, sendo o mesmo escolhido pelo fato de muitos pacientes apresentarem mais de uma regiáo corporal acometida pelas dores. $\mathrm{O}$ instrumento determina um score no valor de 0 a 3 , sendo que o maior score indica uma maior dificuldade funcional em atividades de vida diária, como: vestir-se, abrir e fechar torneiras, segurar em pé no ônibus ou metrô, fazer compras nas redondezas onde mora, entre outras.

Também foram elaboradas questôes sobre o quanto a dor afetava o cotidiano de vida dos sujeitos sob vários aspectos (afazeres domésticos, atividades sociais com amigos, outras atividades de lazer, entre outros), obtendo-se respostas semiabertas e que foram registradas de modo descritivo tal qual foram expressas, e com papel e caneta, para visar a reflexôes e análises posteriores junto aos alunos nos encontros de supervisão.

Foram realizadas avaliações físicas e específicas para a(s) regiáo(ôes) acometida(s), em que era possível identificar algumas limitaçóes em movimentos e referências de sintomas, dolorosos ou não, durante os mesmos, para orientaçóes gerais preventivas de agravos nas atividades de vida diária e planejamentos de algumas atividades corporais ou que envolvessem os segmentos corporais acometidos. Para essas avaliaçóes, foi elaborado um roteiro com descriçóes de regióes corporais e seus movimentos articulares. Foi solicitada, junto aos pacientes, a realização dos movimentos ativos e registrados sintomas dolorosos, se existentes ou não, em cada movimento realizado. Não se pretendeu aqui identificar os déficits em amplitudes angulares das articulaçóes em detalhes e sim apenas identificar déficits gerais em mobilidade e outros aspectos que pudessem estar relacionados às limitaçôes articulares e funcionais do cotidiano. Nesta etapa, também foram obtidas informaçôes junto aos sujeitos avaliados sobre as estratégias utilizadas e, junto às limitaçôes impostas pela doença, para a realizaçáo de atividades do cotidiano de vida.

Após a avaliação, era analisado o caso em supervisão e, posteriormente, definida, junto ao paciente, a necessidade ou não de atendimento individual, ou se seria já encaminhado para as atividades grupais. Eram definidos o dia e horário junto ao paciente, os objetivos gerais iniciais das intervençóes do estágio em Terapia Ocupacional e os recursos terapêuticos a serem utilizados.

\section{Resultados e discussão}

Durante o período, foram encaminhados tanto para a Terapia Ocupacional quanto para a Psicologia, 32 sujeitos com diagnósticos clínicos estabelecidos para LER/DORT, sendo que alguns apresentavam sintomas depressivos. Os sujeitos foram agendados conforme a disponibilidade da agenda dos profissionais e acadêmicos. Dos 32 sujeitos, compareceram para o atendimento de Terapia Ocupacional 28 sujeitos, de ambos os gêneros, que foram encaminhados para atendimentos individuais ou em grupos. A Tabela 1 mostra o perfil geral dos sujeitos.

Conforme observado na Tabela 1, a prevalência foi de sujeitos do gênero feminino. Há, na literatura, vários autores que mencionam a prevalência maior do gênero feminino junto às LERs/DORTs (SALIM, 2003; STRAZDINS; BAMMER, 2004; ALMEIDA; BARBOSA-BRANCO, 2011). Uma das principais relaçóes estaria a dupla jornada de trabalho (trabalho fora de casa e trabalho doméstico), além das condiçóes de trabalho. A escolaridade variou de ensino básico completo e incompleto à superior completo e incompleto, e entre as outras profissões, estavam: professor, assistente administrativo, vendedor, mecânico, entre outras. Entre as principais afecçóes junto aos pacientes: síndrome do túnel do carpo, tenossinovites, tendinopatia (infraespinhal, subescapular, supraespinhal), bursite subacromial, tendinite de Quervain, entre outras, sendo que a

Tabela 1. Perfil geral dos sujeitos atendidos pela Terapia Ocupacional.

\begin{tabular}{|c|c|}
\hline Dados & $(\mathrm{N}=28)$ \\
\hline \multirow{3}{*}{ Faixa etária } & 30 a 40 anos $-25,0 \%(n=7)$ \\
\hline & 41 a 51 anos $-42,8 \%(n=12)$ \\
\hline & Mais de 51 anos $-32,2 \%(n=9)$ \\
\hline \multirow{2}{*}{ Gênero } & Feminino $-78,5 \%(n=22)$ \\
\hline & Masculino $-21,5 \%(n=6)$ \\
\hline \multirow{4}{*}{ Escolaridade } & Ensino básico - $25,0 \%(n=7)$ \\
\hline & Ensino Fundamental - 25,0\% $(n=7)$ \\
\hline & Ensino Médio - 39,2\% $(n=11)$ \\
\hline & Ensino Superior $-10,8 \%(n=3)$ \\
\hline \multirow{5}{*}{ Profissão } & Auxiliar de limpeza - 32,1\% (n=9) \\
\hline & Cozinheiro $-10,7 \%(n=3)$ \\
\hline & Costureiro $-7,2 \%(n=2)$ \\
\hline & Bancário - 7,2\% $(\mathrm{n}=2)$ \\
\hline & Outras $-42,8 \%(n=12)$ \\
\hline \multirow{2}{*}{$\begin{array}{l}\text { Tempo de } \\
\text { afastamento } \\
\text { do trabalho }\end{array}$} & Inferior a dois anos $-21,4 \%(n=6)$ \\
\hline & Superior a dois anos $-78,5 \%(n=22)$ \\
\hline
\end{tabular}


maioria dos sujeitos apresentou mais de um diagnóstico clínico. Os sujeitos residiam na cidade de Santos e na região da Baixada Santista, e os atendimentos individuais ocorreram uma vez por semana, com tempo de duração aproximada de 55 minutos.

$\mathrm{Na}$ Tabela 2, estáo demonstrados os dados obtidos com o Instrumento Health Assessment Questionnaire - $H A Q$, em avaliação inicial junto aos sujeitos.

Conforme observado na Tabela 2, a maioria dos sujeitos apresentou um score superior a 1,1, havendo algumas limitaçóes funcionais em atividades de vida diária, variando as dificuldades conforme o caso e as regiōes corporais acometidas. As regiōes corporais mais acometidas (maiores queixas) e que sofriam riscos de dores em determinados movimentos foram: ombros, cotovelo, punho e mãos, havendo mais de uma região corporal referida com sintomas dolorosos em alguns casos. Deve-se levar em conta, ao se pensar sobre os casos e suas limitaçóes funcionais, na situação de moradia, no contexto familiar e socioeconômico, além da história pregressa de vida e de trabalho, e das características individuais de personalidade.

Alguns dados obtidos acerca da influência das dores no cotidiano de vida evidenciaram as dificuldades em atividades de vida diária: "Não consigo mais estender a roupa no varal, nem lavar as minhas costas no banho, nem varrer o chão" (A.S., auxiliar de limpeza); e ainda: "Afetou bastante... não consigo mais enxugar a louça, lavar a louça, carregar sacola de compras" (C.H., vendedora).

Pela presença de sintomas dolorosos crônicos, os sujeitos apresentavam limitaçóes em algumas atividades de vida diária, aspectos estes que requerem aceitação, adaptaçôes e superaçôes. O sujeito doente e com dor crônica precisa falar e ser escutado, além de que é preciso crer na sua dor (LIMA; TRAD, 2007). A invisibilidade da doença e a possível descrença de alguns podem causar sofrimento. Foi orientado para se evitarem alguns movimentos e posturas de risco - uma das intervençôes: orientaçôes posturais para a prevençáo de agravos -, que podem desencadear as dores; contudo, nem sempre isso é possível no cotidiano de vida dos sujeitos, uma vez que a realizaçáo de algumas tarefas dependeria do auxílio de outros,

Tabela 2. Dados relacionados ao score dos sujeitos, obtidos em avaliação inicial.

\begin{tabular}{cc}
\hline $\boldsymbol{H A Q}$ & $(\mathbf{N}=28)$ \\
\hline Score de 0 a 1 & $21,4 \%(\mathrm{n}=6)$ \\
Score de 1,1 a 2 & $57,2 \%(\mathrm{n}=16)$ \\
Score de 2,1 a 3 & $21,4 \%(\mathrm{n}=6)$ \\
\hline
\end{tabular}

o que envolve o reconhecimento da necessidade de ajuda, vontade em ajudar, disponibilidade de horário, entre tantas outras situaçóes e condições que podem surgir e dificultar os cuidados necessários a si próprio, como: haver conflitos internos psíquicos do sujeito adoecido na aceitação da doença e da incapacidade, não ter parentes capacitados para o auxílio e não ter condiçóes financeiras de pagar pelo serviço, além da falta de acesso facilitado aos serviços públicos de assistência.

Há, frequentemente, dificuldades relacionais encontradas para a realização de algumas tarefas domésticas e que podem gerar desgaste e sofrimento: "Preciso da minha filha para ajudar a fazer as atividades de limpeza [...]" (S.G., auxiliar de limpeza); há, em geral, muitos conflitos internos envolvidos, entre eles a dificuldade em perder papéis sociais, como o de "dona de casa", por exemplo, comprometendo a identidade dos sujeitos. Ainda: "Eu tenho que fazer as coisas de casa, náo tem como... meu marido tem Alzheimer e eu estou cuidando dele" (M.C., costureira), evidenciando a necessidade de "fazer o que deve ser feito" pela falta de outra pessoa que pudesse talvez auxiliar. Os sujeitos acabavam muitas vezes por realizar as tarefas, excedendo suas possibilidades, e sentindo dores após as mesmas. O reconhecimento e a aceitação de suas limitaçôes são fundamentais, bem como a criação de estratégias para dar conta das demandas sem prejuízos físicos e emocionais. A Classificação Internacional de Funcionalidade, Incapacidade e Saúde - CIF evidencia a importância dos aspectos biológicos, psicológicos e sociais envolvidos em integração na funcionalidade humana (SAMPAIO; LUZ, 2009). A interação é complexa e evidencia a necessidade de atuação de equipe multiprofissional e interdisciplinar. A reabilitação física e profissional precisa ser revista sob uma perspectiva em que se possa enxergar o corpo doente de forma integral, a fim de evocar capacidades latentes e ampliar a possibilidade de participação desses indivíduos nos contextos sociais em que vivem (NEVES; NUNES, 2010).

Ainda, muitas vezes, os pacientes sentiam medo de realizar alguns movimentos, por medo de desencadear as dores, conhecido como "cinesiofobia". A partir da abordagem psicossocial, observa-se que indivíduos com dor musculoesquelética desenvolvem síndrome da dor crônica, que está relacionada com o medo de realizar atividades desencadeantes da dor e/ou que gerem a reincidência da dor (FRANCARO et al., 2013). Este aspecto pode levar ao absenteísmo ou desistências da reabilitação física convencional e centrada em modelo biomédico: "Me sinto insegura 
em movimentos, tenho medo da dor" (E.M., auxiliar de serviços gerais).

Os pacientes que eram encaminhados para os atendimentos individuais estavam, em geral, em estado de ansiedade, humor deprimido e sofrimento, muitas vezes identificável através de seus depoimentos iniciais, sendo que o acolhimento e a escuta clínica durante os primeiros atendimentos já propiciava certo alívio, sendo fundamental, portanto, este procedimento terapêutico. Pacientes que se sentem deprimidos por limitaçóes funcionais e com dores crônicas podem ser beneficiados pelas intervençóes da Terapia Ocupacional (SKJUTAR et al., 2010). Dos 28 sujeitos, oito foram encaminhados e permaneceram durante todo o período em atendimento individual, após as sessôes iniciais. Todos os 28 sujeitos foram encaminhados para atividades em grupos em momentos programados. Alguns sujeitos tiveram que interromper o tratamento em decorrência de questóes pessoais (problemas financeiros para o deslocamento, retorno ao trabalho, dificuldades em horários de agendamentos, entre outros). Não houve uma assiduidade nos atendimentos de $100 \%$, conforme já previsto.

Os objetivos das intervenções individuais da Terapia Ocupacional eram elaborados conforme cada caso, mantendo-se a singularidade das questōes e preservando o sigilo necessário para uma boa confiança e conduta terapêutica. Entre os objetivos gerais estabelecidos, estavam: auxiliar no enfrentamento da doença e do afastamento; possibilitar a superaçáo de dificuldades e a descoberta de novas habilidades; promover a melhoria na consciência corporal; minimizar as limitaçôes nas atividades básicas e instrumentais de vida diária, promovendo a autonomia e a independência, entre outras. Os alunos eram orientados a desenvolver planos "A", "B" e às vezes " $\mathrm{C}$ ", para os atendimentos, para contornarem determinadas situaçôes comuns, como, por exemplos, o paciente apresentar muitas queixas dolorosas no dia, indisposição para algumas atividades, entre outras.

Em atendimentos individuais e, a partir de objetivos gerais estabelecidos - porém, não rígidos, uma vez que há um processo relacional e terapêutico envolvido -, eram planejadas as atividades. Os objetivos também podem mudar durante o processo, bem como o planejamento das atividades, cabendo ao terapeuta ocupacional a sensibilidade e a habilidade profissional para perceber as alteraçóes e reflexôes necessárias, neste processo. Entre os recursos terapêuticos utilizados, estavam: toque terapêutico, atividades corporais, relaxamento corporal, orientaçóes "posturais", atividades reflexivas e expressivas (jogos terapêuticos reflexivos, pintura, desenho, colagens, entre outras), sendo esses aspectos discutidos em supervisão. Utilizaram-se, entre as abordagens teóricas, as relacionadas ao processo terapêutico considerado como uma tríade (terapeuta/paciente/atividade), na qual a ocupação é o meio que permite essa interação, objetivando desenvolver um vínculo terapêutico com o participante e atingir o objetivo terapêutico (HAGEDORN, 1999).

Para cada atendimento individual pelos alunos, foi proposta uma atividade que tivesse relaçáo com a anterior, a fim de se explorarem questóes conflituosas, meios e modos de lidar com as situações, as interpretações. Ao longo do processo, em geral, o sujeito começava a ter consciência de aspectos que antes não tinha e das influências de vários aspectos envolvidos nos conflitos, e que estes envolviam suas interpretaçóes e seus modos de ser, de agir, de relacionar-se, bem como de aspectos culturais, sociais, entre outros. Esse processo terapêutico, em geral, não é rápido, dura frequentemente alguns meses, dependendo do número de atendimentos realizados. No decorrer do estágio e, posteriormente, os pacientes foram encaminhados para atividades grupais, fosse para Grupos temáticos ou para Oficinas, no intuito de oferecer trocas de experiências, vivências e dificuldades, e propiciar um ambiente transformador de ideias e opinióes. Alguns sujeitos permaneciam em atendimento em Grupo e atendimento individual, em acordo com o aluno (estagiário) e a necessidade constatada por ambos, após discussóes dos casos e necessidades em supervisão.

\subsection{Os atendimentos em grupos}

Desenvolveram-se dois grupos temáticos, que ocorreram uma vez por semana, com uma hora e meia de duração, havendo de dez a 13 encontros por semestre, com cerca de cinco a seis participantes e uma equipe de estagiários em cada grupo. Os participantes durante o período foram todos do gênero feminino, de diferentes profissóes, sendo o critério principal para a participaçáo, o interesse em se oportunizar para as atividades em grupo.

Em um dos grupos, a equipe foi composta por dois alunos do curso de Terapia Ocupacional e um aluno do curso de Psicologia, ocorrendo de modo interdisciplinar e com supervisão das duas áreas de atuação. Foram propostos papéis de coordenador, vice-coordenador e observador. A proposição de um vice-coordenador foi para auxiliar o coordenador na condução das atividades em grupo. O observador teve o papel de realizar observaçôes e anotaçôes. 
Foi acordado com cada grupo a importância da participação e o período de duração; inicialmente, houve um encontro para as apresentaçôes gerais e a exploração das expectativas. Os encontros foram estruturados a partir de temas, sendo que apenas o inicial era previamente definido, os demais foram elaborados a partir de conteúdos que emergiam nos encontros.

Os objetivos gerais do trabalho em grupo foram: promover espaço de trocas e enfrentamento da situação de afastamento e da doença entre os participantes, de modo a compartilhar sentimentos e vivências; minimizar a culpabilização individual, em alguns casos; auxiliar na busca de estratégias para a realização de atividades básicas e instrumentais de vida diária; promover reflexóes sobre novas possibilidades de vida e trabalho, entre outras. No coletivo, buscam-se atividades que promovam a expressão de expectativas, desejos, sentimentos, além da construção de estratégias para a melhoria da situação atual de vida. Atividades em grupo são muito utilizadas por terapeutas ocupacionais nos Centros de Referência em Saúde do Trabalhador (WATANABE et al., 2013). Lancman (2004) cita que a utilização de atividades expressivas como facilitadoras de dinâmicas de grupo e processos de reflexão grupal constitui recursos tradicionalmente usados por terapeutas ocupacionais. A vivência de atividades, quer sejam atividades corporais, expressivas, artesanais, entre outras, propicia aos trabalhadores se conhecerem, explorarem e descobrirem áreas de interesses, necessidades, limitações, capacidades, bem como desenvolverem habilidades, independência, ampliando, assim, suas perspectivas para o futuro profissional, bem como para as outras esferas da vida (WATANABE et al., 2013).

Ao longo dos atendimentos, alguns aspectos em comum foram identificados. Os participantes, em geral, discorreram sobre aspectos do trabalho, como exigências físicas, poucas pausas, supervisão rígida, ritmo acelerado, entre outros, que geravam desgaste e sofrimento aos sujeitos. Para que essas questóes fossem exploradas, foram utilizadas atividades expressivas, como colagens, desenho, filmes, entre outras, para que tentassem expressar seus sentimentos e, ao mesmo tempo, pudessem perceber diferenças e similaridades em determinadas situaçóes e reaçōes. A partir do momento que o sujeito percebe que não é o único dentro do contexto, em alguns casos, pode se sentir mais aliviado, por dividir, de certa forma, com outros sua condiçâo e seus sentimentos. Após cada atividade, era designado um tempo para reflexôes e discussóes, e às vezes era realizado também um relaxamento corporal. As atividades em grupo visaram a promover laços e redes de suporte social.
Diante do fato de vivenciarem dificuldades no cotidiano de vida, decorrentes da presença de dores crônicas, diversas atividades foram propostas, desde vivências ou simulaçóes de situações críticas em atividades básicas ou instrumentais de vida diária através de teatro, com a possibilidade de proposiçôes "em cena" (pontuais) de meios e métodos alternativos, espontâneos ou dirigidos, ou em atividades corporais, exposição de cenas de filmes e discussóes. O terapeuta ocupacional deve dispor de seu repertório de atividades e adaptá-las às necessidades de cada grupo ou caso, sendo um profissional importante e essencial para compor essas equipes de trabalho.

Ao refletir sobre o "reaprender a fazer", em atividades cotidianas, visando a autonomia e independência, emergiram inicialmente, junto aos sujeitos, sentimento de impotência e angústia diante das limitaçôes; observa-se que uma das grandes dificuldades esteve relacionada ao fato de ter de pedir ajuda no âmbito familiar, na aceitação de modos de fazer do outro e sem impor o seu modo de fazer. Há papéis sociais ocupados e atividades esperadas por determinados papéis, e muitas vezes a perda ou comprometimentos em determinados papéis sociais conquistados e estabelecidos gera sofrimento psíquico. Nestes casos, o apoio e a colaboração efetiva de familiares na execução de tarefas domésticas podem desempenhar um papel importante no processo de restabelecimento das funções, contribuindo muitas vezes também para as relações familiares.

Muitas vezes, há conflitos e dificuldades dentro do âmbito familiar que refletem diretamente nos cuidados pessoais e em tarefas domésticas; por isso, nos encontros, alguns temas necessitaram ser retomados, para que houvesse maiores reflexóes. É importante tomar consciência não só dos movimentos de risco, mas também do contexto afetivo e familiar envolvido, que podem interferir em determinados comportamentos e causar riscos para o surgimento ou agravamento das dores. A vivência dos alunos nos atendimentos propiciou reflexôes acerca dessas questóes, que foram discutidas em supervisão, enriquecendo o processo de aprendizagem. Pôde-se perceber, ao final de cada grupo, que houve, em geral, melhora no autocuidado e na valorização pessoal. A partir do grupo, todos buscaram alternativas e estratégias para saírem do lugar de vitimados que inicialmente apresentaram, se mostrando mais dispostos e confiantes.

Recomenda-se que os Grupos sejam interdisciplinares, o que tende a enriquecer as discussóes e ações, com a sugestão de sempre rodiziar os papéis de coordenador, vice-coordenador e observador, entre a equipe. 


\subsection{Oficinas terapêuticas}

Algumas Oficinas Terapêuticas foram realizadas pelos alunos, nas quais eram previstos dois alunos do curso de Terapia Ocupacional, e tiveram uma duração de aproximadamente três horas cada, em encontros únicos, que ocorreram a cada um ou dois meses, conforme a demanda e a necessidade específica dos casos. Participaram das Oficinas sujeitos que já estavam em atendimentos individuais ou em grupos temáticos. Foram realizadas: "Oficina de fuxico", "Oficina de Bijuterias" e "Oficina de Artesanato". Alencar (2013) descreve com mais detalhes sobre a Oficina de Bijuterias, realizada com algumas mulheres que se sentiam incapazes de realizar algumas atividades domésticas que envolvessem movimentos de coordenação motora fina, mas que, diante do envolvimento e entrosamento em grupo, puderam superar algumas dificuldades, como o medo de desencadear as dores, entre outras.

\subsection{Registros dos atendimentos}

Para o controle dos atendimentos e da frequência dos pacientes, foram elaboradas agendas de controle de horários e frequência. Em caso de mais de duas faltas consecutivas, ligaçôes eram feitas no intuito de verificar o ocorrido e se o paciente manteria sua vaga no atendimento. Nos meses de julho, dezembro e janeiro, não ocorreram atendimentos da Terapia Ocupacional por não terem ocorrido as atividades de estágio durante esses meses.

A Figura 1 mostra o número de atendimentos realizados, individuais e grupais (Grupos Temáticos e Oficinas), realizados no ano de 2011 pelo estágio de Terapia Ocupacional no CEREST-Santos.

Conforme demonstrado, foram realizados, em 2011, 178 atendimentos individuais junto a 28 sujeitos ao longo do ano, sendo que a maioria

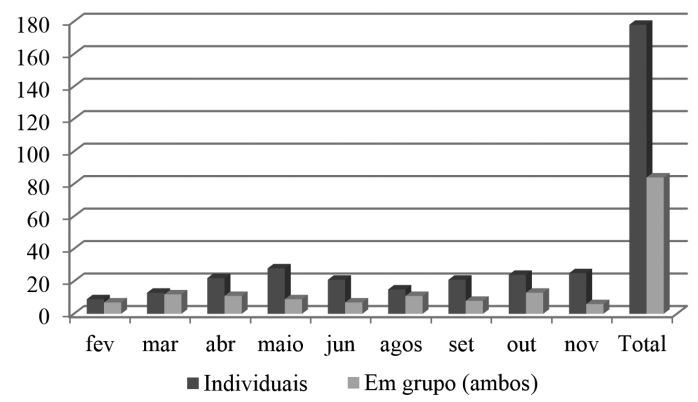

Figura 1. Atendimentos realizados pelo estágio em Terapia Ocupacional no ano de 2011, no CERESTSantos. era do gênero feminino. Destes, permaneceram efetivamente ao longo do ano, em atendimentos individuais, oito sujeitos, sendo um do gênero masculino e sete, do feminino. Nota-se que dois apresentavam depressão diagnosticada clinicamente. Alguns sujeitos do total $(\mathrm{n}=28)$, foram direcionados para os grupos e houve algumas desistências de alguns sujeitos durante o processo, por razóes pessoais. Do total de $n=84$ atendimentos em grupo, ocorreram quatro Oficinas Terapêuticas, com duraçáo aproximada de três horas, sendo os outros $\mathrm{n}=80$ atendimentos referentes aos Grupos Temáticos. Outros atendimentos com outras demandas também ocorreram durante o estágio, não sendo estes relatados aqui por não se tratarem de sujeitos com diagnósticos clínicos estabelecidos ou em processos de investigação para LER/DORT.

Como modo de avaliação do aluno e auxílio no acompanhamento dos casos em supervisão, foi solicitado para que fizessem relatórios descritivos sobre cada atendimento individual ou em grupo, e solicitado para anotarem registros verbais espontâneos dos pacientes, que fossem relevantes para análises e/ou para o serviço oferecido.

\section{Considerações finais}

As atividades individuais desenvolvidas junto aos pacientes propiciaram, ao longo do processo terapêutico, um novo olhar para a situação, e novas interpretaçôes sobre as condiçôes de vida, contribuindo para uma melhora na disposição geral no dia a dia, nos aspectos de autonomia, autoconfiança e independência junto aos pacientes, entre outros, havendo algumas diferenças entre os casos.

As atividades individuais em Terapia Ocupacional junto aos sujeitos em situação de afastamento do trabalho por LER/DORT se fazem, em geral, necessárias pelo contexto físico e mental encontrado, e pelas questóes que envolvem os processos de adoecimento e de afastamento de trabalho. Relatar as experiências se torna uma forma de divulgação do trabalho realizado e este artigo visa a ressaltar a necessidade de se ampliarem as discussões e atuaçôes com equipes multiprofissionais e interdisciplinares junto aos processos de reabilitação em LER/DORT, também com abordagens holísticas, além de evidenciar também a importância do terapeuta ocupacional na equipe.

Espera-se, com este artigo, estimular pesquisas e intervençôes da Terapia Ocupacional junto a esses pacientes. 


\section{Referências}

ALENCAR, M. C. B. Aspectos relacionados aos afastamentos do trabalho por LER/DORT: relato de experiência no CEREST - Santos. In: SIMONELLI, A. P.; RODRIGUES, D. S. Saúde e trabalho em debate: velhas questôes, novas perspectivas. Brasília: Paralelo 15, 2013. p. 273-291.

ALENCAR, M. C. B.; OTA, N. H. O afastamento do trabalho por LER/DORT: repercussōes na saúde mental. Revista de Terapia Ocupacional da USP, São Paulo, v. 22, n. 1, p. 60-67, 2011.

ALMEIDA, P. C. A.; BARBOSA-BRANCO, A. Acidentes de trabalho no Brasil: prevalência, duração e despesa previdenciária dos auxílios-doença. Revista Brasileira de Saúde Ocupacional, São Paulo, v. 36, n. 124, p. 195-207, 2011.

BRASIL. Ministério da Saúde. Doenças relacionadas ao trabalho: manual de procedimentos para os serviços de saúde. Brasília: Ministério da Saúde, 2001. Disponível em: <http://dtr2004.saude.gov.br/susdeaz/instrumento/ arquivo/16_Doencas_Trabalho.pdf $>$. Acesso em: $12 \mathrm{dez}$. 2013.

BUCKLE, P. Ergonomics and musculoskeletal disorders: overview. Occupational Medicine, Guildford, v. 55, n. 3, p. 164-167, 2005.

CROOK, J.; MOLDOFSKY, H. Prognostics indicators of disability after a work-related musculoskeletal injury. In: CHALMERS, A. et al. Fibromyalgia, chronic fatigue syndrome, and repetitive strain injury. New York: Haworth Medical Press, 1995. p. 155-159.

ELKELES, T.; SELIGMAN-SILVA, E. Trajetórias dos distúrbios osteomusculares em dois contextos nacionaisBrasil e Alemanha. In: GLINA, D. M. R.; ROCHA, L. E. Saúde mental no trabalho: da teoria à prática. São Paulo: Roca, 2010. p. 302-334.

FERRAZ, M. B. et al. Cross cultural reliability of the physical ability dimension of the health assessment questionnaire. Journal of Rheumatology, Toronto, v. 17, n. 6, p. 813-817, 1990. PMid:2388204.

FRANCARO, G. A. et al. Comparação entre variáveis psicossociais e de desempenho funcional em um grupo de pacientes com lombalgia crônica. Revista Dor, São Paulo, v. 14, n. 2, p. 119-123, 2013.

GAEDKE, M. A.; KRUG, S. B. F. Quem sou eu? A identidade de trabalhadoras portadoras de LER/DORT. Textos e Contextos, Porto Alegre, v. 7, n. 1, p. 120-137, 2008.

GUTTERRES, C. C. F.; BARKNECHT, K. S. Terapia ocupacional na LER/DORT. Boletim Saúde, Porto Alegre, v. 19, n. 1, p. 85-90, 2005. Disponível em: <http:// www.escoladesaudepublica.rs.gov.br/img2/v19\%20 n1_10terapiaOcupacional.pdf>. Acesso em: 12 dez. 2013.
HAGEDORN, R. Fundamentos da prática em terapia ocupacional. São Paulo: Dynamis Editorial, 1999.

HENNINGTON, E. A. Entre o criativo e o precário: reflexóes sobre constrangimentos e possibilidades do trabalhador da saúde em tempos líquidos. In: GOMEZ, C. M.; MACHADO, J. M. C.; PENA, P. G. L. Saúde do trabalhador na sociedade brasileira contemporânea. Rio de Janeiro: Fiocruz, 2011. p. 433-452.

LANCMAN, S. Construção de novas teorias e práticas em Terapia Ocupacional, Saúde e Trabalho. In: LANCMAN, S. Saúde, trabalho e terapia ocupacional. São Paulo: Roca, 2004. p. 71-83.

LANCMAN, S.; GHIRARDI, M. I. G. Pensando novas práticas em terapia ocupacional, saúde e trabalho. Revista de Terapia Ocupacional da USP de São Paulo, São Paulo, v. 13, n. 2, p. 44-85, 2002.

LEITE, P. C.; SILVA, A.; MERIGHI, M. A. B. A mulher trabalhadora de enfermagem e distúrbios osteomusculares relacionados ao trabalho. Revista da Escola de Enfermagem da USP, São Paulo, v. 41, n. 2, p. 287-291, 2007.

LIMA, M. A. G.; TRAD, L. A. B. A dor crônica sob o olhar médico: modelo biomédico e prática clínica. $\mathrm{Ca}$ dernos de Saúde Pública, Rio de Janeiro, v. 23, n. 11, p. 2672 - 2680, 2007.

LIN, T. Y. et al. Distúrbios osteomusculares relacionados ao trabalho. Revista Médica, São Paulo, v. 80, n. 2, p. 422-442, 2001.

NEVES, R. F.; NUNES, M. O. Da legitimação a (re) significação: o itinerário terapêutico de trabalhadores com LER/DORT. Ciência e Saúde Coletiva, Rio de Janeiro, v. 15, n. 1, p. 211-220, 2010.

RAMOS, M. Z.; TITTONI, J.; NARDI, H. C. A experiência de afastamento do trabalho por adoecimento vivenciada como processo de ruptura ou continuidade nos modos de viver. Caderno de Psicologia Social e Trabalho, Sáo Paulo, v. 11, n. 2, p. 209-221, 2008.

RODRIGUES, D. S.; SIMONELLI, A. P.; LIMA, J. A atuação da terapia ocupacional na saúde do trabalhador. In: SIMONELLI, A. P.; RODRIGUES, D. S. Saúde e trabalho em debate: velhas questóes, novas perspectivas. Brasília: Paralelo 15, 2013. p. 225-239.

SALERMO, V. L.; SILVESTRE, M. P.; SABINO, M. O. Interfaces LER/Saúde Mental: a experiência de um Centro de Referência em Saúde do Trabalhador do Estado de São Paulo. Revista Brasileira de Saúde Ocupacional, São Paulo, v. 36, n. 123, p. 128-138, 2011.

SALIM, C. A. Doenças do trabalho: exclusão, segregação e relaçóes de gênero. São Paulo em Perspectiva, São Paulo, v. 17, n. 1, p. 11-24, 2003.

SAMPAIO, R. F.; LUZ, M. T. Funcionalidade e incapacidade humana: explorando o escopo da classificação internacional da Organização Mundial de Saúde. Cadernos 
de Saúde Pública, Rio de Janeiro, v. 25, n. 3, p. 475-483, 2009.

STRAZDINS, L.; BAMMER, G. Women, work and musculoskeletal health. Social Science Medicine, Canberra, v. 58, n. 6, p. 997-1005, 2004.

SKJUTAR, A. et al. Indicators of need for Occupational Therapy in patients with chronic pain: Occupational Therapists'focus groups. Occupational Therapy International, Copenhagen, v. 17, n. 2, p. 93-103, 2010.

WALSH, I. A. P. et al. Capacidade para o trabalho em indivíduos com lesóes músculo-esqueléticas crônicas. Revista Saúde Pública, São Paulo, v. 38, n. 2, p. 149-156, 2004.
WATANABE, M. et al. A atuação dos terapeutas ocupacionais nos Centros de Referência em Saúde do Trabalhador (Cerest). In: SIMONELLI, A. P.; RODRIGUES, D. S. Saúde e trabalho em debate: velhas questões, novas perspectivas. Brasília: Paralelo 15, 2013. p. 241-272.

WATANABE, M.; NICOLAU, S. M. A Terapia Ocupacional na interface da saúde e trabalho. In: DE CARLO, M. M. R. P.; BARTALOTTI, C.C. Terapia Ocupacional no Brasil: fundamentos e perspectivas. São Paulo: Plexus, 2001. p. 155-171.

YENG, L.T. et al. Distúrbios osteomusculares relacionados ao trabalho. Revista Médica, São Paulo, v. 80, n Pt 2, p. 422-442, 2001. 